Published in final edited form as:

Clin Psychol Psychother. 2012 ; 19(2): 134-140. doi:10.1002/cpp.1778.

\title{
Interpersonal Psychotherapy for Postpartum Depression
}

\author{
Scott Stuart \\ University of lowa, Department of Psychiatry, Psychology, lowa City, lowa, USA University of \\ lowa, Department of Obstetrics and Gynecology, lowa City, lowa, USA University of lowa, IPT \\ Institute, lowa City, lowa, USA 1-293 Medical Education Building lowa City, IA 52242 scott- \\ stuart@uiowa.edu
}

\begin{abstract}
Perinatal depression is prevalent and has a great impact on both mother and infant. There are empirically validated treatments for both postpartum depression and depression during pregnancy. Primary among these is interpersonal psychotherapy, which has been shown to be effective for postpartum women across the spectrum from mild to severe depression. At present, interpersonal psychotherapy is the best validated treatment for postpartum depression and should be considered first-line treatment, especially for depressed breastfeeding women.
\end{abstract}

\section{Keywords}

Interpersonal Psychotherapy; Postpartum Depression; Empirically Validated Treatment; Postnatal Depression

\section{An Overview of Postpartum Depression}

Postpartum Depression (PPD) is a common disorder with a high degree of morbidity. Treatment of PPD is critical. PPD has been estimated to range from 7\% (Gotlib, Whiffen, Mount, Milne, and Cordy, 1989) to 16\% (Whiffen, 1988); a meta-analysis of prevalence studies (M. O'Hara and Swain, 1996) reported an average rate of 13\%, and a recent comprehensive study estimated that the point prevalence for major and minor depression ranged from $8.5 \%$ to $11.0 \%$ during pregnancy and $6.5 \%$ to $12.9 \%$ during the first year postpartum (Gaynes et al., 2005).

DSM-IV has categorized postpartum depression as a subtype of major depression and has added the longitudinal specifier 'with postpartum onset' to describe episodes of major depression that begin within 4 weeks postpartum (American Psychiatric Association, 2000). Depressed mood, decreased energy, difficulty sleeping and appetite disturbances are common. In addition, many women feel hopeless, and some may develop suicidal ideation. Concentration is often decreased, and women with PPD may isolate themselves. Feelings of inadequacy or guilt related particularly to their ability to care for their newborn children are also common.

Untreated PPD has dramatic effects on children's attachment and psychosocial functioning (Murray, 1992; Goodman and Gotlib, 1999). Maternal depression may lead to problems with children such as affective dysregulation, attachment disturbances and poor development of 
cognitive skills (Field, 1992). Depressed mothers have been found to be more punitive, hostile and rejecting, and to be less responsive, sensitive and affectively available to their infants (Field et al., 1985) (Field, Healy, Goldstein, and Guthertz, 1990). Several studies have found that PPD is associated with social and cognitive disturbances in children up to age 4-5 years (Phillipps and O'Hara, 1991) (Caplan et al., 1989). These data point to the importance of early and effective treatment of women to reduce children's exposure to PPD.

Of specific relevance to interpersonal psychotherapy (IPT), perinatal depression is closely linked to social factors, such as being unmarried and having an unplanned pregnancy (Cox, Connor, Henderson, McGuire, and Kendell, 1983). Women from lower social classes and with lower incomes are at higher risk, as are women with poor support from their partners and with poor social support in general (M. O'Hara and Swain, 1996).

Depressed women report that there is a significant discrepancy between the social support they desire during the postpartum period and that which they perceive to have actually received (M. W. O'Hara, 1994). This lack of perceived support occurs in women's relationships with parents, relatives and friends but is most pronounced in their relationships with their partners. The interpersonal relationship between patients and their spouses is reported to be more impaired with postpartum women suffering from depression than with those who are not depressed (M. W. O'Hara, 1994). Husbands often do not share the perception of their depressed wives that they are not being adequately supportive.

This lack of perceived support from significant others during pregnancy has been shown to be a specific risk factor for the occurrence of PPD. IPT targets these specific interpersonal disruptions experienced by women in the postpartum period, leading it to be a natural fit for many postpartum women.

Women with PPD, their families and their clinicians face the dilemma of choosing treatment with psychotherapy, antidepressant medication or their combination with minimal systematic research comparing these modalities to guide them. The factors governing the treatment selected by a woman with PPD are diverse and include knowledge about untreated maternal illness and available treatments, risk perception and individual beliefs (Sit and Wisner, 2005).

It is generally assumed that the efficacy and tolerability of antidepressant medication in PPD is equivalent to that in non-puerperal MDD, but this assumption has not been empirically validated (Abreu and Stuart, 2005). Recent reviews of open trials, case series and case reports of antidepressant medication in women with PPD suggest efficacy (Abreu and Stuart, 2005) (Dennis and Stewart, 2004), but many of these antidepressant trials excluded women who were breastfeeding (Appleby, Warner, Whitton, and Faragher, 1997) (Misri, Reebye, Corral, and Milis, 2004), and none were randomized or controlled.

The treatment options for PPD are further complicated by the lack of prospective, controlled data about potential negative short-term and long-term effects in breastfeeding infants exposed to antidepressant medication. A growing observational database suggests minimal or no short-term adverse effects in infants (Burt et al., 2001) (Misri and Kostaras, 2002) 
(Weissman et al., 2004), but many mothers are still hesitant to take medication without definitive studies regarding long-term effects on child development (Sit and Wisner, 2005).

A recent systematic review reported that patients with major depressive disorder in primary care prefer psychotherapy over antidepressant medication for treatment if psychotherapy is available (van Schaik et al., 2004); this preference is even stronger among postpartum women (A. Whitton, Appleby, and Warner, 1996; A. Whitton, Warner, and Appleby, 1996; Boath and Henshaw, 2001). One study reported that $31 \%$ of breastfeeding women with PPD declined antidepressant medication because they were breastfeeding, and compliance was poor among those who did start due to their concerns about not hearing the baby at night, problematic side effects, potentially harmful long-term effects and the stigma associated with antidepressant medication (Boath and Henshaw, 2001).

In contrast, there is substantial empirical data supporting the use of IPT for PPD, highlighted by two metaanalyses of psychological treatments for PPD. The first showed that IPT for PPD has a substantial effect size (P. Cuijpers, Brannmark, and van Straten, 2008); the second indicated that those psychological interventions for PPD that utilized interpersonal interventions has a greater effect size than those using cognitive interventions (L. Sockel, Epperson, and Barber, 2011). Specific studies include a randomized controlled study ( $n=$ 120) of IPT compared with a waiting list control (M.W. O'Hara, Stuart, Gorman, and Wenzel, 2000) in which IPT was found to be superior on the Beck Depression Inventory (Beck, Steer, and Garbin, 1988) and the Hamilton Rating Scale for Depression (Hamilton, 1960); women receiving IPT also had significantly higher recovery rates. A similar study in which IPT was started prenatally and continued through the postpartum $(n=53)$ also demonstrated significantly better outcome when IPT was compared with treatment as usual (Grote et al., 2009).

In a study examining the impact of patient choice on outcome $(n=23)$, significantly more women with PPD chose IPT than antidepressant medication, particularly when breastfeeding, and outcomes were similar across the IPT alone, antidepressant alone and combined treatment groups (Pearlstein et al., 2006). IPT has also been validated with underserved women with PPD (Zlotnick, Johnson, Miller, Pearlstein, and Howard, 2001; Zlotnick, Miller, Pearlstein, Howard, and Sweeney, 2006; Grote, Swartz, and Zuckoff, 2008; Grote, Zuckoff, Swartz, Bledsoe, and Geibel, 2007).

There is also data supporting the use of IPT for PPD in a group format (Klier, Muzik, Rosenblum, and Lenz, 2001; Reay et al., 2006; Mulcahy, Reay, Wilkinson, and Owen, 2010). This form of IPT may be particularly effective with postpartum women as it creates an immediate social support network that can be utilized as part of the treatment. Larger sample sizes are needed to fully test this approach and to identify mechanisms of change.

In sum, women with PPD frequently prefer psychotherapy over treatment with medication. Their concerns about infant exposure to antidepressant medication with breastfeeding along with a dearth of empirical studies supporting medication for PPD strongly suggest psychotherapy as a first-line treatment. This, coupled with the data supporting IPT in particular for PPD, make a clear case for IPT as the first-line treatment for PPD. 


\section{Interpersonal Psychotherapy for Postpartum Depression: An Overview}

Interpersonal Psychotherapy is a time-limited, dynamically informed psychotherapy that aims to alleviate patients' symptoms and improve their interpersonal functioning (Stuart, 2006; Stuart and Robertson, 2003; Stuart \& Robertson, 2012; Stuart, 2012). A number of elements characterize IPT, particularly for PPD. These can be categorized as the theories, the targets, the tactics and the techniques of IPT (Stuart, 2006). Although individual elements in each of these categories may be shared with other psychotherapeutic approaches, it is their unique combination and interpersonal emphasis that define IPT.

\section{The Structure of Interpersonal Psychotherapy for Postpartum Depression}

Interpersonal psychotherapy for PPD is based on the premise that interpersonal distress is connected to the symptoms of depression. Thus, the threefold targets of treatment are biopsychosocial: psychiatric symptoms, Interpersonal Problem Areas (i.e., the conflicts, transitions and loss experiences in the patient's relationships) and social support (see Table $1)$.

Interpersonal psychotherapy is based on attachment and interpersonal theory (Stuart, 2006). Attachment theory forms the basis for understanding the ways in which people form and maintain relationships as it directs help-seeking behavior and ability to ask for help during crises (Bowlby, 1988). Interpersonal theory conceptualizes that patients' maladaptive communication patterns lead to difficulty in their current interpersonal relationships (Kiesler, 1996).

Interpersonal psychotherapy for PPD follows a biopsychosocial model (Engel, 1980) that asserts that biological, psychological and social factors coalesce within an individual to produce a unique diathesis and response to stress. These are even more apparent in women with PPD as there are clear hormonal and biological changes that occur during pregnancy and after delivery. When faced with a sufficient interpersonal crisis such as a perinatal loss, vulnerable women are likely to become distressed. The biopsychosocial model, therefore, frames psychological difficulties as the response of a unique individual to a specific stressor such as childbirth. Instead of narrowly viewing psychological distress or psychiatric symptoms as a manifestation of a medical illness, IPT conceptualizes the patient's functioning in broad terms as a product of his or her temperament, personality and attachment style, on the basis of a foundation of biological factors such as genetics and physiological functioning, placed in the context of social relationships and broad social support.

This biopsychosocial model is presented directly to the patient as an explanation for her distress. Although medical factors are extremely important, psychological and social factors are also critical. Thus, we no longer use the term 'sick role', instead utilizing the biopsychosocial model that has been used in IPT for over a decade. Depression and distress is far better characterized by a more comprehensive model; the patient is not simply told that she is 'sick', but rather works with the clinician to develop a formulation that includes a number of factors that are contributing to her distress, many of which, such as working to increase social support, she can actively work on from the beginning of treatment. 
The biopsychosocial model leads directly to the specific targets of IPT, namely the biological, psychological and social determinants of the patient's distress (Table 1). This model also supports the use of IPT in combination with psychotropic medications when indicated.

Interpersonal Psychotherapy is also characterized by unique therapeutic tactics that apply to perinatal women. Primary among these are the Interpersonal Inventory, the Interpersonal Problem Areas and the Interpersonal Formulation (Table 1). The Interpersonal Problem Areas for PPD are threefold: (1) Interpersonal Disputes; (2) Grief and Loss; and (3) Role Transitions. The former problem area of Interpersonal Sensitivities/Deficits is no longer used as this domain is more accurately understood as an attachment style rather than an acute interpersonal problem (Ravitz, Maunder, and McBride, 2008; Stuart, 2006, 2012; Stuart and Robertson, 2012).

The reason for the change in conceptualization of the Sensitivities/Deficits from a problem area to an attachment style is threefold. First, every one of the efficacy studies of IPT that have examined the outcome for patients with the various problem areas have shown that outcome is much worse for those patients with the Sensitivities/Deficits problem area. Second, clinical experience confirms this empirical data; all of the extant IPT manuals suggest avoiding the use of this area if possible. Third, the use of this problem area does not fit well with the IPT model of treating acute problems as interpersonal deficits or sensitivities tend to be longstanding problems.

In contrast, the long-standing interpersonal problems described by terms like interpersonal sensitivities or deficits are associated with the fearful attachment style described by Bartholomew and Horowitz (1991), whose model is used in IPT. These individuals have difficulty forming and maintaining relationships, asking for support and have a poor social support network. When they seek treatment, however, it is nearly always for an acute event that is complicated by their attachment style.

For instance, a woman with a fearful attachment style seeks help because of the acute crisis of discovering she is pregnant (role transition) or because her partner, the one stable relationship she has, is threatening to leave (dispute). The key in IPT is to determine what the acute crisis is: what leads the patient to seek treatment right now. When working with patients with fearful attachment styles, the best course in IPT is to work within one of the three acute problem areas, recognizing that the patient's attachment style is a complication that will require the therapist to work more on the therapeutic alliance and to help the patient develop a social support network.

Interpersonal Psychotherapy for PPD follows a 'family medicine' model of care in which short-term treatment of acute distress is provided, then longer term maintenance treatment is arranged as necessary to reduce risk for relapse. It is not required that the therapy sessions be held weekly; in fact, it is common clinical practice to schedule sessions weekly at the onset of treatment and then to move to biweekly sessions once the patient is stable. Once the interpersonal problem is resolved, the therapist should be available to the patient if another crisis occurs, at which time another time-limited course of acute treatment can be 
undertaken (Stuart, 2006). In the interim, the therapist can provide maintenance sessions periodically, an approach that is fully supported by empirical data (Frank, 1991; Frank et al., 2007).

\section{Interpersonal Psychotherapy for Postpartum Depression: Adaptations}

The adaptations of IPT for perinatal women can best be described using the concepts outlined in Table 1. It is critical to appreciate that IPT for perinatal women is simply an adaptation of the basic form of IPT - it is not a new therapy and does not require special additional training. However, therapists providing IPT to perinatal women are well advised to seek additional training in the basics of perinatal physiology and psychology.

The assessment phase of IPT for PPD requires several modifications. A careful initial evaluation must be completed because postpartum women who are not depressed often experience symptoms that might in other contexts be considered symptoms of depression. The care of a newborn, for instance, almost invariably leads to sleep disruptions and decreased energy in postpartum women who are not depressed. Care must be taken to qualitatively ascertain that the physical symptoms reported by postpartum women are more than those that would normally be expected during this time period. Difficulties in becoming pregnant, unwanted pregnancies, prenatal complications and problems in labor can all complicate the course of PPD and should be carefully assessed. There are also often practical considerations for women with PPD such as finding appropriate childcare so that patients can attend the sessions.

The theories and targets of IPT for perinatal women are exactly the same as that outlined for IPT in general (Table 1). The adaptations are evident in the tactics, particularly the different emphases in the interpersonal inventory, and the themes that are common among the interpersonal problem areas. With perinatal women, emphasis should be placed on the woman's relationships with (1) her infant, (2) her partner, (3) her family of origin, (4) her partner's family and (5) her friends.

Most women describe their relationships with their newborns as positive; often, depressed postpartum women will describe their interactions with their newborns as the only ones that they enjoy. Most women also have ambivalent feelings about their babies. Although feeling strongly attached, women often have some feelings of resentment about their loss of spontaneity, their extra workload or the impact their newborns have on their relationships and careers. These ambivalent feelings are often not directly expressed as many women feel pressure to describe only positive feelings about their baby for fear of being seen as a 'bad mother'. Thus, the clinician should be sure and elicit the full range of reactions to motherhood if present. If a woman describes strong negative feelings towards her child, an extensive evaluation should be conducted, with consideration given to diagnoses such as postpartum psychosis. Homicidal ideation towards the child should always be evaluated.

The quality of the marital relationship is an important predictive factor of maternal adjustment during pregnancy and the postpartum (M. W. O'Hara, 1999) and therefore should be carefully assessed. Childbirth affects multiple aspects of the woman's relationship with her partner, including interpersonal and sexual intimacy, the management of an increased 
workload and the couple's interactions with relatives and friends. Many perinatal women note a lack of intimate emotional contact with their partners. Many, particularly those who remain at home after the baby is born, may feel that their husbands are too involved with work at the expense of time at home. In contrast, other women report that they feel conflicted because they devote so much time to the new baby, leaving little time for themselves or their partners. The woman's expectations about feeding (particularly at night), diapering, babysitting and playing with the baby should also be assessed.

Postpartum women may be uninterested in resuming their sexual relationships. A variety of issues can be significant, ranging from physical discomfort, fatigue and body image to the partner's disinterest because of feelings that he is being neglected. One or both partners may be concerned about becoming pregnant again or may disagree about birth control methods (or lack thereof). Because a woman may not feel comfortable raising sexual intimacy concerns in the initial sessions, it is good clinical practice to routinely inquire about her satisfaction with her sexual relationship as treatment progresses. It is also critical to involve the partner in therapy if possible; we routinely invite the woman's partner to at least two sessions of therapy. Educating her partner about the normal physiologic changes that occur postpartum is often extremely helpful in resolving the immediate issues in their sexual relationship.

In the intermediate sessions, IPT for postpartum women often includes specific 'themes' in the interpersonal problem areas. Interpersonal disputes typically involve the woman's partner or immediate family. With partners, the dispute nearly always involves a lack of instrumental support in childcare or a perceived lack of emotional support. Disputes with family often revolve around criticisms about the woman's handling of her newborn, such as sleep practices or breastfeeding, and as with her partner, a perceived or real lack of support from family.

Role transitions often involve decisions that the woman must make regarding returning to work or staying at home. First-time mothers may have difficulty balancing the obligations of their new roles with their other social roles and obligations. Motherhood may involve an unexpected change in priorities or a major shift in self-identity. Whether or not to stay home with their baby is an important decision for many women. Moreover, women may change their minds about working or staying at home once the baby arrives. The most challenging cases are those in which a woman is conflicted about her decision but has little insight into her ambivalence.

Grief and loss, although not as common as disputes and transitions, also includes several perinatal themes. These include previous perinatal losses, such as miscarriages, stillbirths and even previous abortions, which may now be experienced in an entirely different light after the delivery of a healthy infant. The birth of a newborn with disabilities or major medical illness or a very premature delivery may also be experienced as a loss by some women. Reactivation of feelings of grief and loss that may be associated with the woman's own experience of being poorly parented, including abandonment and physical or emotional abuse, may also occur. 
All of the techniques common to IPT are used in the treatment of PPD. However, there are several that are often used more frequently. Among them is psychoeducation. In the initial sessions, the therapist should provide information about the nature and course of PPD and about child development and childcare. Psychoeducation can be exceptionally helpful if used in conjoint sessions as the father may be quite unaware of the postpartum changes that the patient has undergone, not to mention being unaware of child development issues.

Communication analysis is also frequently used in IPT for PPD. Discussion of specific interpersonal incidents in an interpersonal dispute, including a repetition of the dialogue, can help the therapist and patient to identify ways in which the communication may be ambiguous or misleading. The patient may be helped to identify her incorrect assumptions that she has communicated clearly and to identify assumptions that she has understood the communication of others.

Role playing is useful in helping patients to gain insight into their interactions with their partners. In almost all cases, the patient should first take the role of her partner, whereas the therapist plays the part of the patient. This 'role reversal' is extremely helpful in assisting the patient to appreciate her partner's point of view and to assist her in recognizing that he is undergoing significant role transitions as well.

Although the therapist should be active in IPT, frequent offers of advice are generally to be avoided. IPT for PPD, however, is typically quite directive in several areas. These include direct therapist intervention for practical issues that may interfere with therapy such as assisting in finding childcare resources. In addition, the therapist may give direct advice to the patient regarding childcare issues such as helping the child to sleep through the night or regarding problems in nursing or feeding. If possible, of course, the therapist should assist the patient to develop problem-solving techniques rather than to advise the patient.

It should be made clear to the patient at the outset of treatment that IPT is a way to assist patients in their own recovery and a method through which patients can be taught skills that facilitate recovery and reduce the likelihood of relapse. Given the risk of relapse with all patients, it is mandatory that maintenance treatment be discussed. For patients at high risk for relapse, monthly maintenance sessions may be scheduled. For those at low risk, contact at 6 months and if the patient detects emerging symptoms is advisable.

Because of the risk for relapse, acute IPT should be concluded rather than 'terminated'. In other words, treatment is not completely ended or 'terminated' after a fixed number of sessions. Rather, consistent with the research data, all of which demonstrates that acute treatment is not sufficient to prevent relapse (Elkin et al, 1989) and which demonstrates the utility of maintenance IPT (Frank et al, 2007), provision is made for continued maintenance sessions after acute or intensive treatment is concluded. The structure of maintenance treatment may vary depending on the needs of the individual patient, with those at high risk for relapse coming once monthly, for instance, and those at low risk less frequently or on an as-needed basis. For this reason, at the conclusion of acute treatment, it is useful to anticipate any future problems and to help the patient identify signs of relapse so that she can contact the therapist as needed should symptoms begin to re-emerge. 


\section{Conclusion}

Psychosocial interventions are effective for the treatment of PPD, and IPT is foremost among the empirically validated approaches. IPT is a wonderfully intuitive fit for many women with PPD as they typically experience a multitude of biopsychosocial stressors that are associated with their depression, including a number of disrupted interpersonal relationships. Most pronounced are those with their spouse or significant other, but the transitions that occur in the postpartum period usually affect almost all of a woman's relationships as well. IPT offers a specific, problem focused, time-limited and empirically validated treatment for PPD.

\section{Acknowledgments}

This work is supported in part by grants MH072757 and MH074636 from the National Institute of Mental Health (USA).

\section{References}

Abreu A, Stuart S. Medical treatments for postpartum depression. Psychiatric Annals. 2005; 35:568575.

American Psychiatric Association. Diagnostic and statistical manual of mental disorders. 4th (text rev.) ed.. APA; Washington, D.C.: 2000.

Appleby L, Warner R, Whitton A, Faragher B. A controlled study of fluoxetine and cognitivebehavioural counselling in the treatment of postnatal depression. British Medical Journal. 1997; 314(7085):932-936. [PubMed: 9099116]

Bartholomew K, Horowitz L. Attachment styles among young adults: A test of a four category model. Journal of Personality and Social Psychology. 1991; 61:226-244. [PubMed: 1920064]

Beck AT, Steer R, Garbin M. Psychometric properties of the Beck Depression Inventory: Twenty-five years of evaluation. Clinical Psychology Review. 1988; 8:77-100.

Boath E, Henshaw C. The treatment of postnatal depression: a comprehensive literature review. Journal of Reproductive and Infant Psychology. 2001; 19(3):215-248.

Bowlby J. Developmental psychiatry comes of age. The American Journal of Psychiatry. 1988; 145:110. [PubMed: 3276225]

Burt VK, Suri R, Altshuler L, Stowe Z, Hendrick VC, Muntean E. The use of psychotropic medications during breast-feeding. The American Journal of Psychiatry. 2001; 158(7):1000-1009.

Caplan HL, Cogill SR, Alexandra H, Robson KM, Katz R, Kumar R. Maternal depression and the emotional development of the child. The British Journal of Psychiatry. 1989; 154:818-822. [PubMed: 2597889]

Cox JL, Connor YM, Henderson I, McGuire RJ, Kendell RE. Prospective study of psychiatric disorders of childbirth by self-report questionnaire. Journal of Affective Disorders. 1983; 5:1-7. [PubMed: 6220039]

Cuijpers P, Brannmark JG, van Straten A. Psychological treatment of postpartum depression: A metaanalysis. The Journal of Clinical Psychiatry. 2008; 64:103-118.

Dennis CL, Stewart DE. Treatment of postpartum depression, part 1: A critical review of biological interventions. The Journal of Clinical Psychiatry. 2004; 65(9):1242-1251. [PubMed: 15367053]

Elkin I, Shea MT, Watkins JT, Imber SD, Sotsky SM, Collins FL, Glass DR, Pilkonis PA, Leber WR, Doherty JP, Fiester SJ, Parloff MB. NIMH Treatment of depression collaborative research program: I. General effectiveness of treatments. Archives of General Psychiatry. 1989; 46:971982. [PubMed: 2684085]

Engel GL. The clinical application of biopsychosocial models. The American Journal of Psychiatry. 1980; 137:535-544. [PubMed: 7369396]

Field T. Infants of depressed mothers. Development and Psychopathology. 1992; 4:49-66. 
Field T, Healy B, Goldstein S, Guthertz M. Behaviorstate matching and synchrony in mother-infant interactions of nondepressed versus depressed dyads. Developmental Psychology. 1990; 26:7-14.

Field T, Sandberg D, Garcia R, Vega-Lahr N, Goldstein S, Guy L. Pregnancy problems, postpartum depression, and early mother-infant interactions. Developmental Psychology. 1985; 21:11521156.

Frank E. Interpersonal psychotherapy as a maintenance treatment for patients with recurrent depression. Psychotherapy. 1991; 28:259-266.

Frank E, Kupfer DJ, Buysse DJ, Swartz HA, Pilkonis PA, Houck PR, Rucci P, Novick DM, Grochocinski VJ, Stapf DM. Randomized trial of weekly, twice-monthly, and monthly interpersonal psychotherapy as maintenance treatment for women with recurrent depression. The American Journal of Psychiatry. 2007; 164:761-767. [PubMed: 17475735]

Gaynes, BN.; Gavin, N.; Meltzer-Brody, S.; Lohr, KN.; Swinson, T.; Gartlehner, G.; Brody, S.; Miller, WC. Perinatal depression: prevalence, screening accuracy, and screening outcomes.. In: AHRQ. , editor. Evidence report/technology assessment no. 119. AHRQ; Rockville, MD: 2005.

Goodman SH, Gotlib IH. Risk for psychopathology in the children of depressed mothers: A developmental model for understanding mechanisms of transmission. Psychological Review. 1999; 106:458-490. [PubMed: 10467895]

Gotlib IH, Whiffen VE, Mount JH, Milne K, Cordy NI. Prevalence rates and demographic characteristics associated with pregnancy and the postpartum. Journal of Consulting and Clinical Psychology. 1989; 57:269-274. [PubMed: 2785127]

Grote NK, Swartz HA, Geibel SL, Zuckoff A, Houck PR, Frank E. A randomized controlled trial of culturally relevant, brief interpersonal psychotherapy for perinatal depression. Psychiatric Services. 2009; 60(3):313-321. [PubMed: 19252043]

Grote NK, Swartz HA, Zuckoff A. Enhancing interpersonal psychotherapy for mothers and expectant mothers on low incomes: Adaptations and additions. Journal of Contemporary Psychotherapy. 2008; 38(1):23-33. [PubMed: 21822328]

Grote NK, Zuckoff A, Swartz H, Bledsoe SE, Geibel S. Engaging women who are depressed and economically disadvantaged in mental health treatment. Social Work. 2007; 52(4):295-308. [PubMed: 18232240]

Hamilton M. A rating scale for depression. Journal of Neurology, Neurosurgery, and Psychiatry. 1960; 23:56-62.

Kiesler, DJ. Contemporary interpersonal theory and research: Personality, psychopathology, and psychotherapy. John Wiley \& Sons; New York: 1996.

Klier CM, Muzik M, Rosenblum KL, Lenz G. Interpersonal psychotherapy adapted for the group setting in the treatment of postpartum depression. The Journal of Psychotherapy Practice and Research. 2001; 10:124-131. [PubMed: 11264336]

Misri S, Kostaras X. Benefits and risks to mother and infant of drug treatment of postnatal depression. Drug Safety. 2002; 25(13):903-911. [PubMed: 12381212]

Misri S, Reebye P, Corral M, Milis L. The use of paroxetine and cognitive-behavioral therapy in postpartum depression and anxiety: A randomized controlled trial. The Journal of Clinical Psychiatry. 2004; 65(9):1236-1241. [PubMed: 15367052]

Mulcahy R, Reay RE, Wilkinson RB, Owen C. A randomised control trial for the effectiveness of group interpersonal psychotherapy for postnatal depression. Archives of Women's Mental Health. 2010; 13(2):125-139.

Murray L. The impact of postnatal depression on infant development. Journal of Child Psychology and Psychiatry. 1992; 33:543-561. [PubMed: 1577898]

O'Hara, MW. Postpartum depression: Causes and consequences. Springer-Verlag; New York: 1994.

O'Hara, MW. Postpartum mental disorders.. In: Sciarra, JJ., editor. Gynecology and obstetrics. Vol. 6. Harper and Row; Philadelphia: 1999. p. 1-17.

O'Hara M, Swain A. Rates and risk of postpartum depression: A meta-analysis. International Review of Psychiatry. 1996; 8:37-54.

O'Hara MW, Stuart S, Gorman L, Wenzel A. Efficacy of interpersonal psychotherapy for postpartum depression. Archives of General Psychiatry. 2000; 57:1039-1045. [PubMed: 11074869] 
Pearlstein TB, Zlotnick C, Battle CL, Stuart S, O'Hara MW, Price AB, Grause MA, Howard M. Patient choice of treatment for postpartum depression: A pilot study. Archives of Women's Mental Health. 2006; 9(6):303-308.

Phillipps LH, O'Hara MW. Prospective study of postpartum depression: 41/2year follow-up of women and children. Journal of Abnormal Psychology. 1991; 100:151-155. [PubMed: 2040765]

Ravitz P, Maunder R, McBride C. Attachment, contemporary interpersonal theory and IPT: An integration of theoretical, clinical, and empirical perspectives. Journal of Contemporary Psychotherapy. 2008; 38(1):11-22.

Reay R, Fisher Y, Robertson M, Adams E, Owen C, Kumar R. Group interpersonal psychotherapy for postnatal depression: A pilot study. Archives of Womens Mental Health. 2006; 9(1):31-39.

van Schaik DJ, Klijn AF, van Hout HP, van Marwijk HW, Beekman AT, de Haan M, van Dyck R. Patients' preferences in the treatment of depressive disorder in primary care. General Hospital Psychiatry. 2004; 26(3):184-189. [PubMed: 15121346]

Sit DKY, Wisner KL. Decision making for postpartum depression treatment. Psychiatric Annals. 2005; 35(7):577-585.

Sockel L, Epperson CN, Barber J. A meta analysis of treatments for perinatal depression. Clinical Psychology Review. 2011; 31:839-849. [PubMed: 21545782]

Stuart S. Interpersonal psychotherapy: A guide to the basics. Psychiatric Annals. 2006; 36:542-549.

Stuart, S. Interpersonal psychotherapy. American Psychiatric Press; Washington DC: 2012.

Stuart, S.; Robertson, M. Interpersonal psychotherapy: A clinician's guide. Edward Arnold Ltd.; London: 2003.

Stuart, S.; Robertson, M. Interpersonal psychotherapy: A clinician's guide. 2nd edition. Edward Arnold Ltd.; London: 2012.

Weissman AM, Levy BT, Hartz AJ, Bentler S, Donohue M, Ellingrod VL, Wisner KL. Pooled analysis of antidepressant levels in lactating mothers, breast milk, and nursing infants. The American Journal of Psychiatry. 2004; 161(6):1066-1078. [PubMed: 15169695]

Whiffen V. Vulnerability to postpartum depression: A prospective multivariate study. Journal of Abnormal Psychology. 1988; 97:467-474. [PubMed: 3204233]

Whitton A, Appleby L, Warner R. Maternal thinking and the treatment of postnatal depression. International Journal of Psychiatry. 1996; 8:73-78.

Whitton A, Warner R, Appleby L. The pathway to care in post-natal depression: Women's attitudes to post-natal depression and its treatment. The British Journal of General Practice. 1996; 46(408): 427-428. [PubMed: 8776916]

Zlotnick C, Johnson SL, Miller IW, Pearlstein T, Howard M. Postpartum depression in women receiving public assistance: Pilot study of an interpersonal-therapy-oriented group intervention. The American Journal of Psychiatry. 2001; 158:638-640. [PubMed: 11282702]

Zlotnick C, Miller IW, Pearlstein T, Howard M, Sweeney P. A preventive intervention for pregnant women on public assistance at risk for postpartum depression. The American Journal of Psychiatry. 2006; 163(8):1443-1445. [PubMed: 16877662] 


\section{Key Practitioner Message}

- IPT is a first-line evidence-based treatment for postpartum depression.

- IPT can be easily modified for postpartum depression.

- Partners can be included in IPT for postpartum depression.

- Group IPT for postpartum depression is effective for depression. 

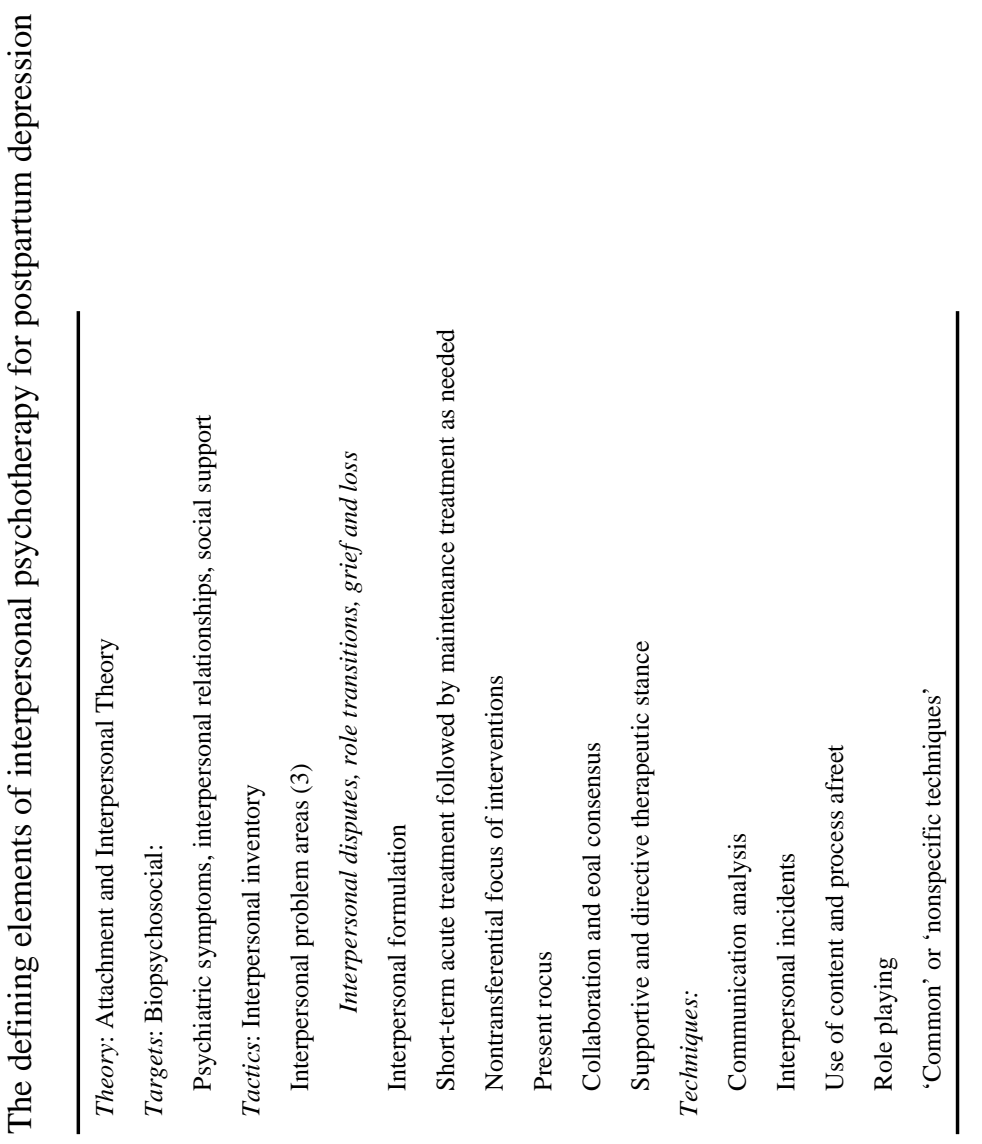

Clin Psychol Psychother. Author manuscript; available in PMC 2014 August 22. 